\title{
Some properties of a three-part learning set task ${ }^{\prime}$
}

MYMON GOLDSTEIN, LONG ISLAND UNIVERSITY DAVID A. EASTERLY, TRENTON STATE COLLEGE

In a three-part learning set task, human Ss exhibited pronounced learning-to-learn effects, but rarely mastered a dependency that related Part 3 to Parts 1 and 2. Correlations with reference measures of ability and achievement were small.

Two-part learning set designs were introduced recently by Goldstein \& Weber (1966) and explored further by Goldstein \& Wright (1966). A similarly constructed three-part learning set design occupies us here. It is featured in a psychometric study that seeks to bridge the "two disciplines" gap (Cronbach, 1957) still separating psychometrics from experimental psychology. Method

The new three-part learning set design is shown in Fig. 1, which contains the first three out of a total run of 60 problems. Parts 1 and 2 involve two-choice discriminations of the type $x x$ and yy; Part 3 involves a two-choice discrimination of the type xy. Reinforcement is assigned as follows: Either the left (L) side or the right (R) is arbitrarily designated as correct in Part 1 and independently in Part 2. The scheme for Part 1 and Part 2 jointly is therefore LL, LR, RL or RR. Whenever the positions agree for Parts 1 and 2 (Schemes $L L$ and RR) the correct choice in Part 3 is the stimulus that was present in Part 1; whenever the positions disagree for Parts 1 and 2 (Schemes LR and RL) the correct choice in Part 3 is the stimulus from Part 2. Note that the positions of the stimuli during Part 3 are irrelevant.

The number of trials per part per problem is arbitrary. The data to be reported are for two trials per part, hence six trials per problem. The first trials of Part 1 and Part 2 necessarily involve guesses, but the second trials can be mastered readily on the basis of the first. Part 3 is different in that its first trial does not require a guess; it can be mastered on the basis of the dependency that relates Part 3 to Parts 1 and 2. Trial 2 of Part 3 can be mastered the same way, but more usually on the basis of information from Trial 1 of Part 3.

The foregoing task was administered as follows. Each trial made use of a single printed sheet of paper. This sheet contained two stimuli, below each of which there was an opaque square composed of erasable ink. $S$ indicated his choice of a stimulus by erasing the square below it, and his erasure exposed a printed check mark if the choice was correct, but a blank space if the choice was incorrect. Accordingly, each protocol required 360 sheets of paper, equivalent to 360 trials, since there were two trials per part $x$ three parts per problem x 60 problems. These 360 sheets were bound

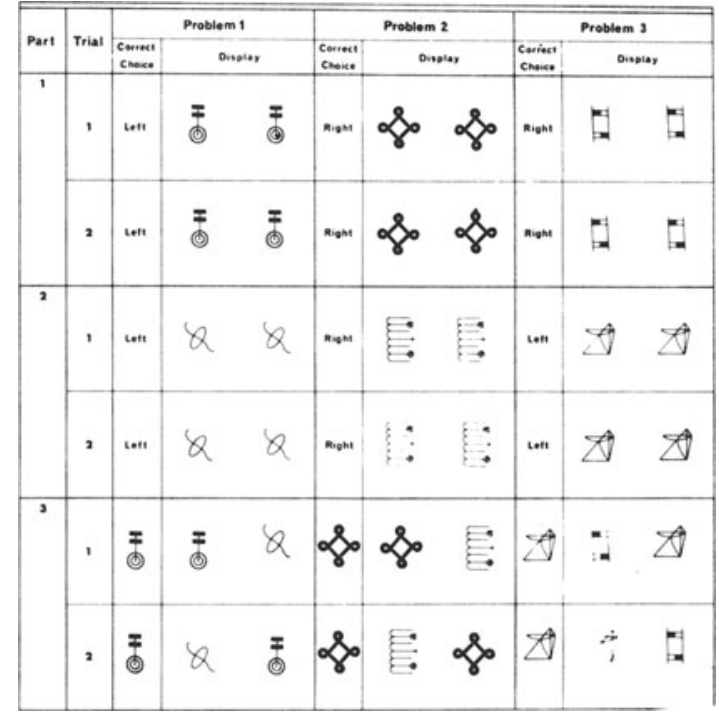

Fig. 1. Design of the experiment. There were 60 problems in all.

into a single test booklet, and $\mathrm{S}$ sequenced from trial to trial by turning pages. There was no time limit.

The Ss were 159 twelfth graders at Princeton (N.J.) High School. ${ }^{2}$ Eighteen reference scores were obtained from school records and are identified in Table 1.

\section{Results and Discussion}

Performance curves for the three-part learning set task are plotted in Fig. 2. The curve for Part 3, Trial 1

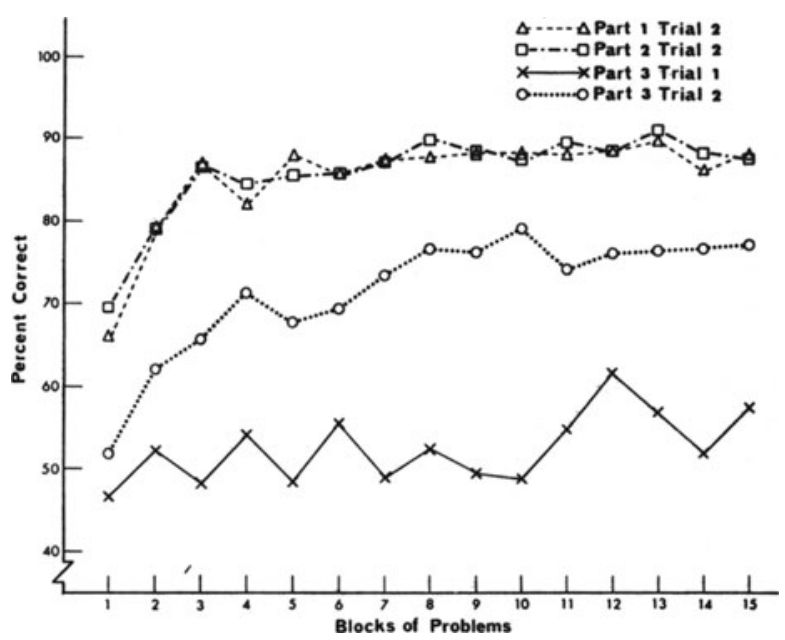

Fig. 2. Changes in performance as a function of problems, with trials distinguished. There are four problems per block. 
Table 1. Means, SD's, Selected Correlations, and Loadings on All Significant Factors

Correlations with

\begin{tabular}{|c|c|c|c|c|c|c|c|c|c|c|c|}
\hline \multicolumn{3}{|c|}{ Variable } & \multirow[b]{2}{*}{$M$} & & \multicolumn{4}{|c|}{ Three-Port Learning Set } & \multicolumn{3}{|c|}{ Factor Loadings? } \\
\hline Source & Year & Score & & $S D$ & $\begin{array}{l}\text { Part } 1 \\
\text { Trial } 2\end{array}$ & $\begin{array}{l}\text { Port } 2 \\
\text { Trial } 2\end{array}$ & $\begin{array}{l}\text { Part } 3 \\
\text { Trial } 1\end{array}$ & $\begin{array}{l}\text { Part } 3 \\
\text { Trial } 2\end{array}$ & $\begin{array}{c}\text { Factor } \\
I\end{array}$ & $\begin{array}{c}\text { Factor } \\
\text { II }\end{array}$ & $\begin{array}{c}\text { Factor } \\
\text { III }\end{array}$ \\
\hline \multirow[t]{4}{*}{ Three-Part Learning Set } & 1966 & Part 1, Trial 2 & 51.3 & 9.0 & -- & .93 & .21 & .71 & .20 & .93 & .06 \\
\hline & & Part 2, Trial 2 & 51.6 & 9.0 & .93 & -- & .20 & .71 & .22 & .92 & .07 \\
\hline & & Part 3, Trial 1 & 31.7 & 5.5 & .21 & .20 & -- & .19 & -.01 & .24 & -.07 \\
\hline & & Part 3, Trial 2 & 43.0 & 13.8 & .71 & .71 & .19 & -- & .27 & .72 & .10 \\
\hline Grade Point Average & & & 2.5 & 0.6 & .35 & .37 & .05 & .45 & .68 & .26 & .25 \\
\hline \multirow[t]{3}{*}{ Henmon-Nel son Intell. } & 1963 & $1 Q$ & 118.4 & 12.3 & .32 & .33 & .01 & .34 & .78 & .17 & .16 \\
\hline & 1965 & 10 & 120.0 & 17.1 & .31 & .33 & -.01 & .35 & .77 & .18 & .21 \\
\hline & & IQ-pctile & 83.4 & 18.7 & .30 & .33 & .01 & .36 & .83 & .15 & .15 \\
\hline \multirow[t]{14}{*}{ Nelson-Denny Reading } & 1963 & Vocab & 121.5 & 22.3 & .31 & .34 & -.01 & .34 & .83 & .13 & .13 \\
\hline & & Vocab-petile & 84.2 & 24.1 & .27 & .31 & .03 & .29 & .82 & .10 & .09 \\
\hline & & Comp. & 121.6 & 20.3 & .32 & .32 & .02 & .37 & .82 & .16 & .18 \\
\hline & & Comp-pctile & 82.9 & 21.4 & .29 & .30 & .03 & .30 & .77 & .14 & .09 \\
\hline & & Total & 121.7 & 20.0 & .34 & .35 & .00 & .38 & .92 & .16 & .19 \\
\hline & & Total-pctile & 85.3 & 21.3 & .32 & .35 & .04 & .31 & .85 & .14 & .10 \\
\hline & 1965 & Vocab & 41.3 & 14.9 & .30 & .30 & -.05 & .34 & .84 & .12 & .32 \\
\hline & & Vocab-pctile & 80.0 & 21.6 & .30 & .30 & .00 & .33 & .87 & .10 & .20 \\
\hline & & Comp & 44.9 & 12.5 & .25 & .28 & .01 & .32 & .81 & .09 & .18 \\
\hline & & Comp-pctile & 72.4 & 25.0 & .25 & .28 & .03 & .31 & .80 & .09 & .15 \\
\hline & & Total & 36.3 & 25.4 & .30 & .32 & -.02 & .36 & .90 & .11 & .28 \\
\hline & & Total-pctile & 77.5 & 22.3 & .30 & .32 & .01 & .35 & .92 & .10 & .19 \\
\hline & & Rate & 315.7 & 119.2 & .08 & .11 & -.09 & .14 & .27 & -.02 & .90 \\
\hline & & Rate-pctile & 69.2 & 27.2 & .11 & .12 & -.03 & .16 & .35 & -.02 & .81 \\
\hline
\end{tabular}

a Based on complcte $22 x 22$ matrix of correlations from which only four columns are reported here. The factor loadings tabulated were obtained atter l'arimar rotation.

reveals no group trend whatsoever, and indicates that most Ss did not master the relationship whereby Parts 1 and 2 determined reinforcement in Part 3 . But the curves for Part 1, Trial 2 and Part 2, Trial 2 provide clear evidence of rapid learning to a group asymptote, and show that learning-to-learn effects like those studied by Harlow (1949) emerged strikingly in the present context as well. Learning-to-learn effects are also exhibited by the curve for Part 3, Trial 2, but it is displaced downward, probably because tendencies to respond positionally were established by Parts 1 and 2 and interfered with the object identity requirement of Part 3.

Data similar to those of Fig. 2 were obtained by counting the number of Ss who attained a terminal run of 10 or more consecutive correct responses on a designated trial. For Part 3, Trial 1, the number attaining such a terminal run was only five $(3.1 \%)$. The corresponding figures for the other trials were: Part 1, Trial 2, $97(61.0 \%)$; Part 2, Trial 2, $92(57.9 \%)$; Part 3, Trial 2, 61 (38.4\%).

The most important psychometric data are summarized in Table 1, whose salient features are as follows. Within the three-part learning set task, correlations between trials are high except where Part 3 ,
Trial 1 is involved. The exceptional status of Part 3, Trial 1 presumably results from the near-chance level of performance it evoked in almost every S. All trials except Part 3, Trial 1 correlated about .3 with grade point average, the Henmon-Nelson Intelligence scores and the Nelson-Denny Reading scores other than Rate and Rate-Percentile. Factor I seems to be an IQ-achievement factor, and is not heavily represented in the three-part learning set task. Factor II seems to be a learning set factor, and is not heavily represented outside the three-part learning set task.

\section{References}

CRONBACH, L. J. The two disciplines of scientific psychology. Amer. Psychologist, 1957, 12, 671-684.

GOLDSTEIN, M., \& WEBER, R. J. Symbols via learning set. Percept. mot. Skills, 1966, 22, 351-358.

GOLDSTEIN, M., \& WRIGHT, P. D. An uncomplicated but difficult two-part learning set task. Psychon. Sci, 1966.

HARLOW, H. F. The formation of learning sets. Psychol. Rev., 1949, $56,51-65$.

Notes

1. This study received support from the Secondary School Science Project at Princeton University in furtherance of its activities under grants from the National Science Foundation.

2. The efforts of Chester R. Stroup, Superintendent of Schools, and Kenneth E. Michael, Principal, are greatly appreciated. 